03

\title{
Распространение одиночной волны давления по области разряда микроволнового диапазона длин волн в воздухе при средних давлениях
}

\author{
(С) В.Л. Бычков, ${ }^{1}$ Л.П. Грачев, ${ }^{2}$ И.И. Есаков, ${ }^{3}$ А.В. Семенов ${ }^{3}$ \\ ${ }^{1}$ Московский государственный университет им. М.В. Ломоносова, \\ 119991 Москва, Россия \\ ${ }^{2}$ Московский радиотехнический институт РАН, \\ 117519 Москва, Россия \\ ${ }^{3}$ Московский университет им. С.Ю. Витте, \\ 115432 Москва, Россия \\ e-mail: iesakov@yandex.ru \\ Поступило в Редакцию 4 марта 2021 г. \\ В окончательной редакции 15 мая 2021 г. \\ Принято к публикации 15 мая 2021 г.
}

Описаны результаты экспериментов по распространению волны давления с ударно-волновым передним фронтом через газовую область, возбужденную импульсным свободно локализованным разрядом микроволнового диапазона дли волн. Разряд реализовывался в воздухе при давлении от 14 до 100 Torr в фокусной области квазиоптического электромагнитного пучка микроволнового диапазона длин волн. Опыты выявили три типа взаимодействия газодинамического импульса с областью возбужденной разрядом в после разрядном режиме. Конкретный тип взаимодействия определяется исходной структурой разряда и временем задержки прохождения газодинамического импульса через возбужденную область.

Ключевые слова: аэродинамика, микроволновый разряд, волна давления.

DOI: $10.21883 / J T F .2021 .11 .51522 .52-21$

\section{Введение}

Для снижения сопротивления при сверхзвуковых скоростях известны два основных физических эффекта при подаче дополнительного тепла в поле течения. Первый эффект заключается в снижении плотности в передней части обтекаемого тела (из-за повышения температуры), это предполагает использование постоянного подогрева. Другой механизм представляет собой объединение эффектов низкой плотности в следе за зоной нагрева и поля течения вокруг тела, это может привести к созданию совершенно иного поля течения. Величина влияния этого эффекта на поле течения отличается для различных аэродинамических форм обтекаемого тела.

Внедрение плазмы в высокоскоростные аэродинамические поля течений с присущими им сильными градиентами физических параметров приводит к рождению множества физических процессов, включая сложные взаимодействия, происходящие при прохождении ударной волны (УВ) [1,2]. Создание плазмы осуществляется с помощью электрических разрядов различного типа. Стримерные (нитевидные) разряды были исследованы в целях поиска методов снижения аэродинамического сопротивления при сверхзвуковых и гиперзвуковых скоростях. Эти разряды могут быть очень неоднородными и в пространстве, и во времени. Часто они создаются с помощью высокочастотных разрядов и СВЧ (микроволновых) разрядов. Наибольшее внимание исследователей с точки зрения эффективности воздействия на потоки привлекает СВЧ разряд [2,3]. Это связано прежде всего с его высокой энергетической эффективностью. Практически вся энергия источника СВЧ, кроме отраженной от разрядной области и рассеиваемой, потребляется таким разрядом при давлениях выше 30 Torr. Формирование сфокусированного квазиоптического электромагнитного пучка микроволнового диапазона длин волн позволяет в его фокусной области, удаленной от окружающих элементов, зажигать импульсный газовый электрический разряд [2-6]. Энергетическое воздействие импульсным микроволновым разрядом и лазерным излучением вызвало значительный интерес в прошедшие несколько десятилетий как многообещающая техника для управления потоками на высоких скоростях и сверхвысоких [1,2].

Хорошо известны успешные эксперименты в этой области исследований [7-13].

Так, группы исследователей под руководством Колесниченко, Лашков и Машека [3,4] провели ряд экспериментов для исследования воздействия СВЧ плазмы на сопротивление тупого цилиндра при числе Маха 1.7 в набегающем потоке при статическом давлении $p_{\infty}=8 \mathrm{kPa}$ и статической температуре $T_{\infty}=200 \mathrm{~K}$. Микроволновый пульс был произведен клистроном, работающим на уровне $9 \mathrm{GHz}$ с пиковой мощностью $210 \mathrm{~kW}$ и продолжительностью пульса $\tau=1.2$ к $2.2 \mu \mathrm{s}$. Разряд произвел несколько плазмоидов вверх по течению тупого цилиндра. 
Для исследования характеристик реализующейся плазмы группа Экстона [5] провела эксперимент по исследованию взаимодействию СВЧ плазмы с тупым цилиндром при числе Маха $\mathrm{M}=6$ в набегающем потоке при статическом давлении $p_{\infty}=0.4 \mathrm{kPa}$ и статической температуре $T_{\infty}=70 \mathrm{~K}$. Микроволновый пульс был произведен клистроном (на уровне $15.8-17.3 \mathrm{GHz}$ ) с пиковой мощностью $425 \mathrm{~kW}$ и продолжительностью пульса $\tau \leq 3.5 \mu$ s.

Группа Лашкова-Машека [4] проводила эксперименты для оценки взаимодействия микроволнового разряда на тупом и полусферическом цилиндрах при числе Маха $\mathrm{M}=2.1$ в воздухе в набегающем потоке при статическом давлении $p_{\infty}=3.3 \mathrm{kPa}$ и статической температуре $T_{\infty}=159 \mathrm{~K}$. Последующие эксперименты проводились во многих работах этого коллектива $[7,8]$.

Проделанные эксперименты показали значительное влияние плазмы СВЧ разряда на параметры набегающего потока, и оптимальные условия для приложений исследуются в новых работах [9-15].

В опытах для зажигания разряда при невысоких газовых давлениях используются герметичные рабочие камеры. При этом контрольные излучения должны быть выведены из камеры через оптически прозрачные иллюминаторы. Это вызывает сложности при интерпретации результатов измерений. Путем пропускания через разрядную область газодинамического возмущения (ГИ) с ударно-волновым (УВ) передним фронтом могут быть осуществлены акустические измерения. Описанию таких экспериментов и их результатов и посвящена настоящая статья. Настоящая работа является продолжением аналогичных исследований, описанных в работе $[2,6]$. Выполненные эксперименты наглядно показали, что в зависимости от исходного вида безэлектродного свободно локализованного импульсного разряда и времени задержки от его окончания до момента зондирования после разрядной области ГИ существуют три типа влияния этой области на параметры зондирующего импульса.

\section{1. Экспериментальные условия}

Эксперименты проводились на установке, схема которой приведена на рис. 1.

В опытах использовалась горизонтально расположенная герметичная цилиндрическая рабочая камера диаметром $60 \mathrm{~cm}$ и длиной $160 \mathrm{~cm}[2,6]$. Ее внутренняя боковая поверхность покрыта поролоном. Давление атмосферного воздуха в камере р могло устанавливаться в диапазоне от 10 Torr до атмосферного значения с минимальным шагом 1.5 Torr.

Через радиопрозрачный торец рабочей камеры в нее в виде квазиоптического пучка электромагнитного излучения (ЭИ) может излучаться линейно поляризованная электромагнитная (ЭМ) волна с длиной волны $\lambda=8.9 \mathrm{~cm}$. ЭИ фокусируется на оси камеры в ее центральной области. В опытах использовались одиночные

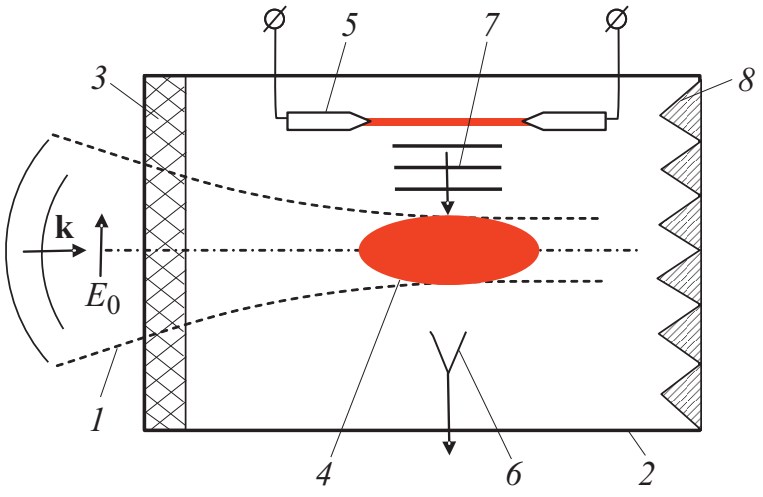

Рис. 1. Схема эксперимента: 1 - пучок ЭИ, $2-$ герметичная рабочая камера, 3 - радиопрозрачное окно, $4-$ разрядная область, 5 - разрядник - генератор акустического возмущения, 6 - приемник акустической волны, 7 - зондирующая УВ, 8 - поглотитель ЭИ.

ЭМ импульсы длительностью $\tau_{p u l}=40 \mu \mathrm{s}$. Мощность пучка ЭИ в различных импульсах могла устанавливаться в диапазоне от $P_{\min } \approx 10 \mathrm{~kW}$ до $P_{\max }=500 \mathrm{~kW}$. В фокусной плоскости пучок ЭИ имел гауссово поперечное распределение амплитуды электрической составляющей ЭМ волны $E$ : в вертикальном направлении $E=E_{0} \exp \left(-x^{2} / a^{2}\right)$ при $a=5.2 \mathrm{~cm}$, а в горизонтальном $E=E_{0} \exp \left(-y^{2} / b^{2}\right)$ при $b=2.5 \mathrm{~cm}$. Протяженность фокусной области пучка ЭИ в осевом направлении с уровнем поля $E \gtrsim 0.8 E_{0}$ имеет размер $z_{0} \approx 8 \mathrm{~cm}$. При этом в соответствии с формулой [2-4] $P=\left[E_{0}^{2} /\left(2 Z_{0}\right)\right](\pi a b / 2)$, где $Z_{0}=120 \pi$ - волновое сопротивление свободного пространства. При $P_{\min }$ поле равно $E_{0}=600 \mathrm{~V} / \mathrm{cm}$, а при $P_{\max }$ величина поля $E_{0}=4 \mathrm{kV} / \mathrm{cm}$.

Для зажигания разряда в ЭМ поле уровень его электрической составляющей $E_{0}$ должен быть больше минимального - критического поля пробоя $E_{\mathrm{cr}}$ при заданном давлении газа $p$. Для СВЧ пробоя воздуха поле $E_{\mathrm{cr}}=42 p,[\mathrm{~V} / \mathrm{cm}][2,4]$ при единицах измерения $p$, как и во всех аналогичных формулах, [Torr]. В этой формуле учтено, что в опытах при экспериментальном значении $\lambda$, чему соответствует круговая частота $\omega=2 \cdot 10^{10} 1 / \mathrm{s}$, образующаяся разрядная плазма будет столкновительной, т. е. в ней $v_{c}>\omega$, где частота столкновения плазменных разрядных электронов с молекулами воздуха $v_{c}=4 \cdot 10^{9} \cdot p,[1 / \mathrm{s}][2,4]$.

В экспериментальном диапазоне изменения $E_{0}$ с учетом формулы для $E_{\text {cr }}$ воздух может быть пробит в диапазоне давления $p$ от 14 до 100 Torr. В этом диапазоне свободно локализованный надкритический СВЧ разряд будет зажигаться в диффузном или стримерном виде [2]. Граница между этими видами разряда $E_{\text {thres }}(p)$ достаточно резкая и при поле $E_{0}$, близком к $E_{\mathrm{cr}}$, находится в диапазоне $p=(35-40)$ Torr. При проведении наших опытов зависимость $E_{\text {thres }}(p)$ была экспериментально уточнена. Результаты этих опытов приведены на рис. 2. 
В опытах, как показано на рис. 1, зондирующее разрядную область газодинамическое возмущение создается импульсным линейным газовым разрядом. Естественно, что энергия реализующегося при этом газового возмущения растет с ростом давления воздуха $p$. Из рис. 2 следует, что в опытах при $p=30$ Torr при варьировании поля $E_{0} \geq E_{\text {cr }}$ будет меняться и вид разряда. Так, при $E_{0} \geq 1.3 \mathrm{kV} / \mathrm{cm}$ до $E_{0}=2 \mathrm{kV} / \mathrm{cm}$ он будет реализовываться в диффузном, а при $E_{0}>2 \mathrm{kV} / \mathrm{cm}-$ в стримерном виде.

На рис. 2 приведены фотографии разряда в воздухе при $p=30$ Torr в фокусной области СВЧ пучка в диффузном и стримерном виде.

Из анализа опытных фотографий следует, что горизонтальная протяженность разрядных областей имеет масштаб $z_{d i s} \approx 10 \mathrm{~cm}$. Он и задал межэлектродное расстояние разрядника, генерирующего цилиндрический зондирующий ГИ, $z=8 \mathrm{~cm}$. К электродам этого разрядника через соответствующий ключ может подключаться предварительно заряженный до напряжения $U=15 \mathrm{kV}$ конденсатор емкостью $C=1 \mu \mathrm{F}$. При этом значении $U$ и давлении в рабочей камере $p=30$ Torr при замыкании ключа каждый раз между электродами загорается линейный импульсный разряд. Он и является источником зондирующего ГИ.

В опытах приемник этого импульса смонтирован по линии, перпендикулярной оси этого разряда, на расстоянии $L=56 \mathrm{~cm}$ симметрично электродам. Его осно-

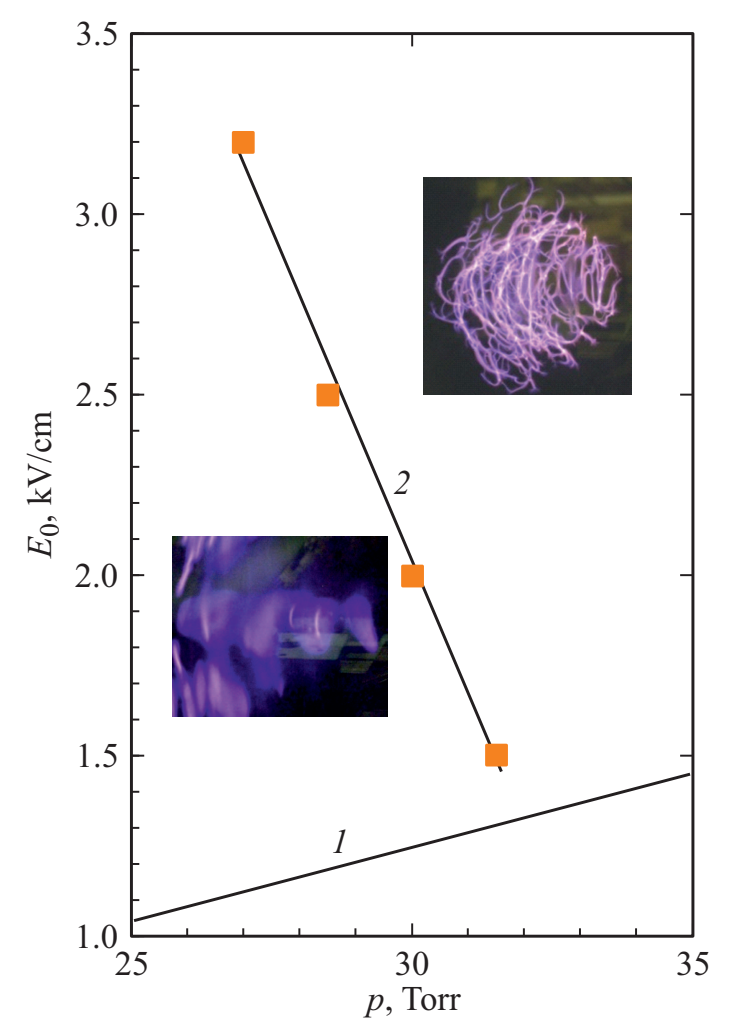

Рис. 2. Граница между диффузным и стримерным видами надкритического микроволнового разряда: $1-E_{\mathrm{cr}}(p)$, 2 - эксперимент.

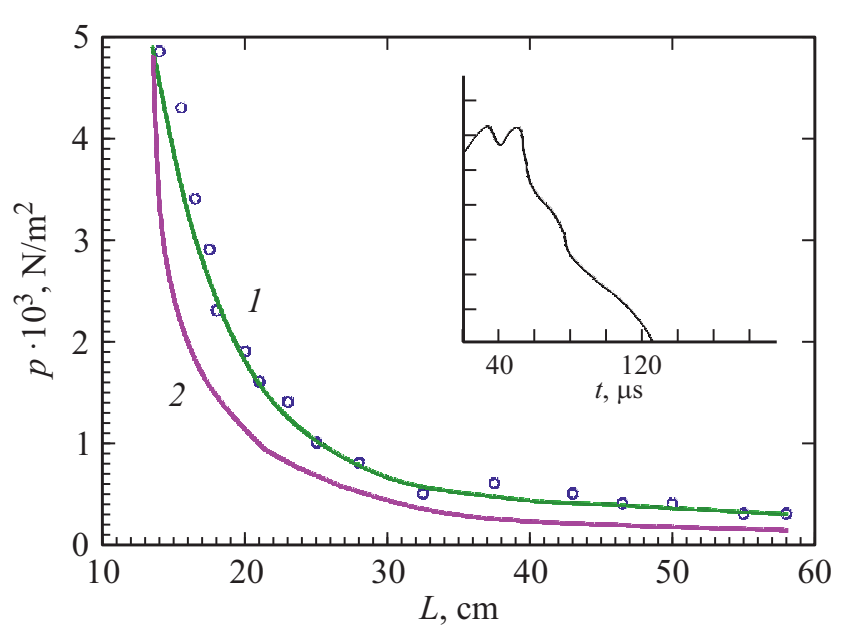

Рис. 3. Зависимость избыточного давления на фронте ГИ, измеренная вдоль траектории его движения: 1 - эксперимент, 2 - теория.

ва - пьезодатчик из титаната бария диаметром $5 \mathrm{~mm}$ и толщиной $0.6 \mathrm{~mm}$. Примененное крепление пьезодатчика позволяет практически полностью задемпфировать его собственные колебания. Измерительная цепь фиксирует перепады давления с минимальной длительностью $1 \mu \mathrm{s}$ и практически без искажения отслеживать его плавные изменения с характерными временами масштаба миллисекунд. Время между последовательными пробоями этого разрядника в опытах было не меньше $1 \mathrm{~min}$.

На рис. 3 помещена экспериментальная кривая измерений избыточного давления на фронте газодинамического возмущения вдоль траектории его движения без зажигания разряда. На нем же помещена и расчетная зависимость, полученная на основе соотношений, приведенных в работе [2] для треугольного начального профиля волны. Можно видеть их относительное совпадение.

На рис. 3 приведена и характерная осциллограмма зондирующего сигнала. На ней горизонтальный масштаб $20 \mu \mathrm{s} /$ div. Вертикальный масштаб условен. Он пропорционален избыточному давлению. Из осциллограммы следует, что зондирующее возмущение имеет ударный передний фронт.

\section{2. Результаты основных экспериментов}

Основные опыты проводились при давлении в камере $p=30$ Torr. В них варьировались поле $E_{0}$ и время задержки зондирующего ГИ по отношению к моменту включения поля $t_{\text {delay. }}$.

На рис. 4 помещен набор осциллограмм, соответствующих полю $E_{0}=2.2 \mathrm{kV} / \mathrm{cm}$, т.е. стримерному разряду. На них правые осциллограммы - это результаты контрольных экспериментов, т. е. получены при отсутствии разряда, а левые получены уже с включением разряда и разном времени $t_{\text {delay }}$. 


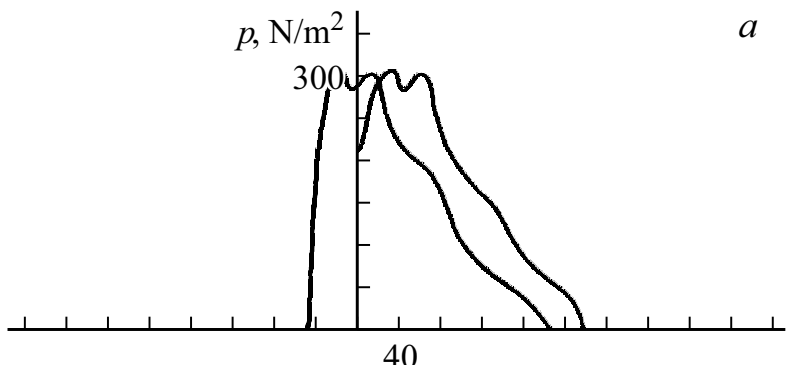

$t, \mu \mathrm{s}$

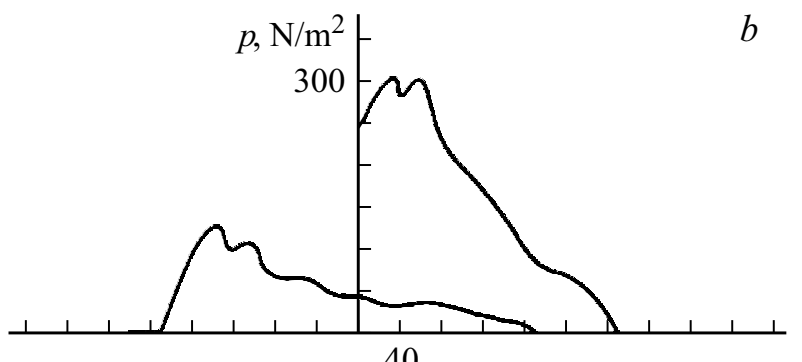

$t, \mu \mathrm{s}$

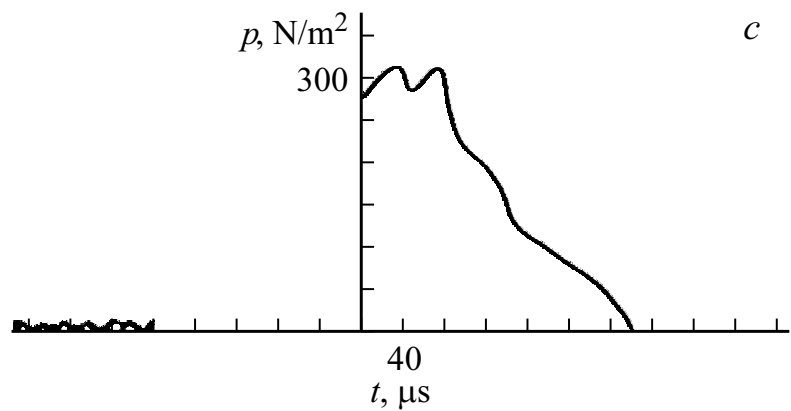

Рис. 4. Типы взаимодействия слабой УВ с плазмой безэлектродного разряда.

Рис. 4, $a$ соответствует сравнительно большому времени задержки $t_{\text {delay }}=0.2 \mathrm{~s}$. При этом реализуется первый тип взаимодействия контрольной УВ с после разрядной областью разряда. Из рисунка следует, что зондирующий импульс доходит до приемника быстрее, а его амплитуда и форма практически сохраняются. Такой тип взаимодействия в экспериментах при данном $p$ и $E_{0}$ фиксировался при всем времени задержки $t_{\text {delay }}>8 \cdot 10^{-2} \mathrm{~s}$.

При меньшем времени $t_{\text {delay }}$ в диапазоне от $5 \cdot 10^{-3}$ до $8 \cdot 10^{-2} \mathrm{~s}$ реализуется второй тип взаимодействия контрольного газодинамического импульса с после разрядной областью разряда. Соответствующая ему осциллограмма приведена на рис. $4, b$. Из нее следует, что при этом типе взаимодействия зондирующий импульс доходит до приемника быстрее, его амплитуда существенно уменьшается, а передний фронт становится наклонным. Уменьшается и площадь фиксируемого импульса по сравнению с контрольным.

И наконец, при еще меньшем времени $t_{\text {delay }}$ реализуется третий тип взаимодействия, проиллюстрированный на рис. 4, $c$. При нем структура зондирующего газодинамического импульса полностью разрушается.
Мы указывали, что в экспериментах варьировалось поле $E_{0}$ и могли реализовываться не только стримерная, но и диффузная формы разряда. При этом во всем диапазоне реализации диффузной формы в опытах фиксировались только первый и второй вид взаимодействия контрольного ГИ с разрядной областью. Причем даже при $t_{\text {delay }}=0$ контрольный ГИ, меняя свои характеристики в соответствии с рис. $4, b$, не разрушаясь полностью, проходил через разрядную область.

Таким образом, эксперименты выявили три типа взаимодействия импульсного газового возмущения с ударным передним фронтом при его прохождении через разрядную область.

\section{Конфликт интересов}

Авторы заявляют, что у них нет конфликта интересов.

\section{Список литературы}

[1] В.Л. Бычков, Л.П. Грачев, И.И. Есаков, А.В. Семенов. ЖТФ, 90 (8), 1283 (2020).

[2] Л.П. Грачев, И.И. Есаков, К.В. Александров, А.А. Раваев, Л.Г. Северинов, К.В. Ходатаев. Газовый электрический разряд в квазиоптическом СВЧ пучке (АО „МРТИ PAH“, M., 2015)

[3] Труды института общей бизики РАН. Физика и химия газовых разрядов в пучках СВЧ-волн (Наука, М., 1994), т. 47.

[4] Высокочастотный разряд в волновых полях, под ред. А.Г. Литвак В сб. науч. тр. ИПФ АН СССР (ИПФ АН СССР, Горький, 1988)

[5] А.С. Зарин, А.А. Кузовников, В.М. Шибков. Свободно локализованный СВЧ-разряд в воздухе (Нефть и газ, М., 1996)

[6] Л.П. Грачев, И.И. Есаков, Г.И. Мишин, М.Ю. Никитин, К.В. Ходатаев. ЖТФ, 55 (5), 972 (1985).

[7] V. Fomin, P. Tretyakov, J.-P. Taran. Aerospace Sci. Technol., (8), 411 (2004).

[8] D.J. Knight. Propulsion Power., 24 (6), 1153 (2008).

[9] Y. Kolesnichenko, V. Brovkin, S. Leonov, A. Krylov, V. Lashkov, I. Mashek, A. Gorynya, M. Ryvkin. AIAA Paper 2001-0345 (2001).

[10] V. Lashkov, I. Mashek, Y. Anisimov, V. Ivanov, Y. Kolesnichenko, M. Ryvkin, A. Gorynya. AIAA Paper 2004-0671 (2004).

[11] R. Exton, R. Balla, B. Shirinzadeh, G. Herring, J. Fugitt, C. Lazard, K. Khodataev. Phys. Plasmas, 8 (11), 5013 (2001).

[12] V.A. Lashkov, A.G. Karpenko, R.S. Khoronzhuk, I.Ch. Mashek. Phys. Plasmas, 23, 052305 (2016). https://doi.org/10.1063/1.4949524

[13] A.I. Saifutdinov, E.V. Kustova, A.G. Karpenko, V.A. Lashkov. Plasma Phys. Rep., 45, 602 (2019). https://doi.org/10.1134/S1063780X19050106

[14] V.G. Brovkin, P.V. Vedenin. J. Appl. Phys., 128, 113301 (2020). DOI: $10.1063 / 5.0016249$

[15] A.I. Saifutdinov, E.V. Kustova. J. Appl. Phys., 129, 023301 (2021). https://doi.org/10.1063/5.0031020 